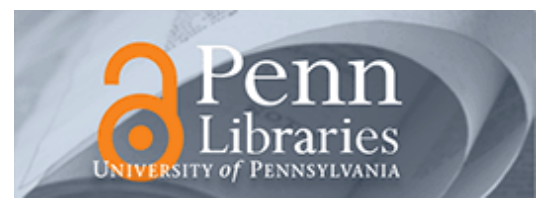

University of Pennsylvania ScholarlyCommons

$4-21-2006$

\title{
INFORMATION GAP TASKS: Their Multiple Roles and Contributions to Interaction Research Methodology
}

Teresa Pica

University of Pennsylvania, teresap@gse.upenn.edu

Hyun-Sook Kang

University of Pennsylvania

Shannon Sauro

University of Pennsylvania

Follow this and additional works at: https://repository.upenn.edu/gse_pubs

Part of the Education Commons

\section{Recommended Citation}

Pica, T., Kang, H., \& Sauro, S. (2006). INFORMATION GAP TASKS: Their Multiple Roles and Contributions to Interaction Research Methodology. Retrieved from https://repository.upenn.edu/gse_pubs/93

(C) Cambridge University Press 2006. Reprinted from Studies in Second Language Acquisition, Volume 28, Issue 2, April 2006, pages 301-338.

Publisher URL: http://dx.doi.org/10.1017/S027226310606013X

This paper is posted at ScholarlyCommons. https://repository.upenn.edu/gse_pubs/93

For more information, please contact repository@pobox.upenn.edu. 


\title{
INFORMATION GAP TASKS: Their Multiple Roles and Contributions to Interaction Research Methodology
}

\author{
Abstract \\ This article describes how information gap tasks can be designed as instruments for data collection and \\ analysis and as treatments in interaction research. The development of such tasks is illustrated and data \\ are presented on their role in drawing learners' attention to second language (L2) forms that are difficult \\ to notice through classroom discussion alone. Because the tasks presented here are closed-ended and \\ precision oriented and require the exchange of uniquely held information, they promote modified \\ interaction among participants and orient their attention to form, function, and meaning. These processes \\ can be observed by the researcher during task implementation. Thus, the tasks reduce researcher \\ dependence on externally applied treatments and analytical instruments not integral to the interaction \\ itself. To illustrate this methodology in use, we report on a study in which six pairs of intermediate-level \\ English L2 learners carried out three types of information gap tasks in their classrooms. They first read \\ passages on familiar topics, whose sentences contained L2 forms that were low in salience and difficult \\ to master but developmentally appropriate. To complete the tasks, the learners were required to identify, \\ recall, and compare the forms, their functions, and their meanings. Data revealed close relationships \\ among learners' attentional processes, their recall of form, function, and meaning, and the interactional \\ processes that supported their efforts.

\section{Disciplines} \\ Education

\section{Comments} \\ (c) Cambridge University Press 2006. Reprinted from Studies in Second Language Acquisition, Volume 28, \\ Issue 2, April 2006, pages 301-338. \\ Publisher URL: http://dx.doi.org/10.1017/S027226310606013X
}




\title{
INFORMATION GAP TASKS
}

\author{
Their Multiple Roles and \\ Contributions to Interaction \\ Research Methodology
}

\author{
Teresa Pica, Hyun-Sook Kang, and Shannon Sauro \\ University of Pennsylvania
}

\begin{abstract}
This article describes how information gap tasks can be designed as instruments for data collection and analysis and as treatments in interaction research. The development of such tasks is illustrated and data are presented on their role in drawing learners' attention to second language (L2) forms that are difficult to notice through classroom discussion alone. Because the tasks presented here are closed-ended and precision oriented and require the exchange of uniquely held information, they promote modified interaction among participants and orient their attention to form, function, and meaning. These processes can be observed by the researcher during task implementation. Thus, the tasks reduce researcher dependence on externally applied treatments and analytical instruments not integral to the interaction itself. To illustrate this methodology in use, we report on a study in which six pairs of intermediate-level English L2 learners carried out three types of information gap tasks in their classrooms. They first read passages on familiar topics, whose sentences contained L2 forms that were low in salience and difficult to master but developmentally appropriate. To complete the tasks, the learners were required to identify, recall, and compare the forms,
\end{abstract}

In carrying out the design and implementation of the tasks in this article, we have worked most closely with Kristine Billmyer and MaryAnn Julian, and also Jin Ahn, Marni Baker-Stein, Mara BlakeWard, Lyn Buchheit, Junko Hondo, Sharon Nicolary, and Jack Sullivan. Among the many graduate students who have provided assistance are Vivian Chen, Yao Chen, Yi-Chen Chen, Cathy Fillman, Leslie Harsch, Hanae Katayana, Ji Hwan Kim, Atsuko Matsui, Lisa Mullen, Amy Nichols, Matthew Salvatore, Margaret Skaarup, Lauren Smith, Cheng-Chen Tseng, Debbie Tsui, Melissa Yi, Wei-Chieh $\mathrm{Yu}$, and Mira Yun.

Address correspondence to: Teresa Pica, Hyun Sook Kang, or Shannon Sauro, University of Pennsylvania, 3700 Walnut St., Philadelphia, Pennsylvania 19104-6216; e-mail: teresap@gse.upenn.edu, hyunkang@dolphin.upenn.edu, totoro2@dolphin.upenn.edu. 
their functions, and their meanings. Data revealed close relationships among learners' attentional processes, their recall of form, function, and meaning, and the interactional processes that supported their efforts.

This article focuses on the design and implementation of information gap tasks, which can be usefully employed both as instruments for data collection and analysis and as treatments in interaction research. The roles and contributions of information gap tasks in classroom and research contexts are first described and compared and then the issues and challenges surrounding their implementation are discussed. A general methodology is presented that makes it possible for the same task to be used as both an authentic classroom activity for teaching and learning and a reliable instrument for data collection on the learning process. After this presentation, a study that employed this methodology in the construction and implementation of three different tasks is described.

\section{INFORMATION GAP TASKS AS RESEARCH INSTRUMENTS}

Information gap tasks were introduced to the SLA research context by Long (1980) in order to address questions on input and interaction. Since that time, they have also come to serve as reliable instruments for gathering data on a variety of instructional interventions and learning processes as these arise during both learner-learner and learner-native speaker (NS) interaction. The origins of information gap tasks can be traced to the classroom, in activities that ask learners to find differences between individually held pictures, to order sentences into stories, or to restore portions of incomplete maps and charts (e.g., Brumfit \& Johnson, 1979; Ur, 1981, 1988). As they carry out these activities, learners engage in functional, meaning-focused second language (L2) use and gain access to input for learning. Sources that have described and referred to information gap tasks include professional references (e.g., Ur, 1981, 1988), scholarly publications (e.g., R. Ellis, 2003; Krashen \& Terrell, 1983; Mackey \& Gass, 2005; Nunan, 1989), and student textbooks (e.g., Anger, Fuchs, Pavlick, \& Segal, 1988; Harmer \& Surguine, 1987).

Among the most productive tasks for SLA are those in which interaction must lead to a specific goal or outcome, and reaching this outcome requires a verbal exchange of information (e.g., R. Ellis, 2003; Pica, Kanagy, \& Falodun, 1993). Such tasks set up conditions for participants to modify their interaction through the negotiation of meaning (Long, 1980; Varonis \& Gass, 1985). As learners repeat and rephrase utterances to make sure that their information is accurate and understood, they also draw attention to the forms that encode these utterances. This can be seen in (1), in which two English lan- 
guage learners exchanged information about their individually held pictures in order to reassemble a picture story hidden from their view. Suno followed up Yaka's initial statement by questioning Yaka's information, repeating "she" but using "is" rather than Yaka's original verb, "called." Yaka incorporated "is" into his response and recoded "called" to "is calling." The conversation then moved toward task completion. Were this a learner-NS experience, the data would have been far richer in NS input, as Yaka might have heard a recast such as "in one of them she called someone," followed by a question such as "who was she calling?"

(1) Yaka: So I just have one more two picture. One of them she called someone.

Suno: She is?

Yaka: She is calling someone.

(Pica, Lincoln-Porter, Paninos, \& Linnell, 1996, p. 74)

Information gap tasks have been the focus of comparison studies on learners' negotiation, collaboration, and encoding of form, function, and meaning for different tasks and classroom groupings (e.g., Doughty \& Pica, 1986; Duff, 1986; Kowal \& Swain, 1994; Newton \& Kennedy, 1996; Swain, 1998; Swain \& Lapkin, 2001). However, they have more commonly served as instruments for data collection in studies on classroom turntaking, teacher versus student control of interactions, and group and pair participation patterns (e.g., Doughty \& Pica; Pica \& Doughty, 1985a, 1985b). For the classroom processes examined in these studies, data revealed that the information distribution and design of the tasks play a more influential role than interlocutor variables. Information gap tasks have also been used to collect descriptive and frequency data on learner and NS generation of input, output, and feedback (e.g., Crookes \& Rulon, 1988; Mackey, 1999; Mackey, Oliver, \& Leeman, 2003; Oliver, 1995, 2000; Plough $\&$ Gass, 1993) and to address questions on input comprehension and comprehensibility (e.g., Gass \& Varonis, 1985, 1994; Pica, 1991; Pica, Young, \& Doughty, 1987). Whereas NSs have been found to offer more elaborated input, nonnative speakers (NNSs) have been found helpful in providing each other with feedback signals and responses that contain modified output.

As illustrated by this brief overview, information gap tasks have been used in research primarily as a source of data on input, interaction, and interlanguage or as a context for the application of a treatment such as a feedback move. Seldom, however, have information gap tasks served as research treatments, despite evidence of their role in activating SLA processes, as illustrated in (1). To date, the work of Loschky and Bley-Vroman (1993) remains one of the most influential publications on treatment tasks. Following their guidelines, a task can be designed so that its successful outcome depends on the comprehension and expression of information encoded with a specific linguistic form that learners are developmentally ready to acquire, but that proves difficult to master. For example, an information gap task designed as an interview would establish contexts for questions. The task could then be used cross- 
sectionally to collect data on question development. Repeated over time, the task could also be used longitudinally to track sequences in question formation or to shed light on attentional and interactional processes for question development. Loschky and Bley-Vroman suggested that the most helpful tasks for SLA are those in which L2 forms are task essential, meaning that a task cannot be accomplished unless participants focus on a specific form. Locatives, for example, would be essential to completion of an object placement task. Most tasks fall short of this ideal, however, and are more likely to need forms that are useful, but not essential, for completion. In the case of an interview, for example, questions - though a likely choice-would not be essential because imperatives or statements of request could be used in their place.

In an approach that privileges form usefulness, information gap tasks might also be designed to encourage learners to attend to specific linguistic forms that are difficult to learn. Among these are forms with low perceptibility, infrequency of occurrence, or limited transparency between the forms and the functions or meanings they encode (Harley, 1993; Long, 1996). This perspective is somewhat consistent with that of focus-on-form, advanced by Long (1991) and continued by Long and Robinson (1998). Applied to the model proposed by Loschky and Bley-Vroman (1993), an interview task could be designed to elicit steps in a recipe, directions to a sequence of destinations, or instructions for a lab experiment. A successful interview would depend on accurate elicitation and encoding of the functional categories of enumeration, directionality, and reference, through forms such as articles, pronouns, and deictic devices. Thus, attention to a form-despite its lack of salience-would be essential for obtaining the recipe, reaching the destinations, or completing the experiment.

The versatility and robustness of information gap tasks for SLA research continues to grow. Increasingly, information gap tasks are used to focus learners' attention on form, function, and meaning and to study their attentional processes and responses to feedback with respect to these forms (Iwashita, 2003; Leeman, 2003; Leow, 1997; Mackey, 1999; Mackey \& McDonough, 2000; Philp, 2003). It is evident from these studies that information gap tasks are excellent resources for addressing theoretical questions on SLA. Their pedagogical origins make them especially favorable for research on classroom concerns, especially those that relate to broad theoretical issues of interest to the field, such as learning processes and outcomes (e.g., Doughty \& Williams, 1998).

\section{INFORMATION GAP TASKS IN CLASSROOM PERSPECTIVES}

\section{Controlled Conditions}

Despite their origins in classroom practice, information gap tasks used in research have been implemented primarily under conditions more typical of 
a controlled environment than a classroom setting. Research conditions have included monitored sessions outside the classroom (Long, 1985; Pica, Holliday, Lewis, Berducci, \& Newman, 1991; Pica, Holliday, Lewis, \& Morgenthaler, 1989; Pica et al., 1996; Pica, Young, \& Doughty, 1987), special researcher visits to actual classrooms (Pica, 1991), and breaks during regular class meetings (Doughty \& Pica, 1986). Some studies have gathered data by implementing tasks in authentic classrooms, but as extracurricular activities added on to the regular classroom agenda (Newton \& Kennedy, 1996; Williams \& Evans, 1998). Data have also been collected during individual, small group, or interview sessions controlled by a researcher, often on a short-term basis. Such practices guarantee uniform delivery of task treatments across multiple participants, with consistent timing in task implementation. The research design can be maintained with reliability and consistency, so that task directions are followed carefully and tasks are implemented uniformly across different learners and within a comparable time frame. These approaches have shed light on the processes and outcomes of what is often referred to as instructed SLA (DeKeyser, 2003; Doughty, 2003).

Data collected through the use of information gap tasks under controlled conditions have been highly reliable and informative (particularly with respect to theoretical questions). However, concerns have been raised about the authenticity of the data with respect to the term instructed SLA (e.g., Byrnes, 2000). First, the learners who have provided the data are, first and foremost, subjects in a study and only secondarily are they students in a classroom. Additionally, teachers have questioned the usefulness and relevance of the data to actual classroom life (Pica, 1994). Also, as both DeKeyser (2003) and Doughty (2003) noted, studies implemented under controlled conditions lack the ecological validity that research during actual class time can offer.

These concerns have yet to be resolved and might better be addressed in sociolinguistic projects than in SLA research. Many interventions designed to promote SLA can be considered instructional if the treatment they offer is characterized by feedback, explanation, or pedagogical moves associated with instruction (e.g., Krashen \& Seliger, 1975). These features lend authenticity to the use of such interventions in research on instructed SLA outside of the classroom context. However, it is important to think of instructed SLA in the classroom as a distinct, multifaceted experience, as learners come together to learn an L2, meeting collectively and often frequently over a period of time. Despite the familiarity such a context can offer, classroom learners are often more reluctant to respond to checks on their comprehension or to seek clarification when they interact with their teachers than when they interact with interlocutors outside of the classroom (Pica, 1987). The classroom provides a distinct context for the study of instructed SLA, and the information gap task can play a vital role in addressing questions about the interactions and interventions that occur there. The meaning-focused classroom appears especially relevant in this regard. 


\section{Meaning-Focused Contexts}

Although it has been shown that much of an L2 can be learned through focus on meaning, there is increasing evidence that learning that results from a focus on meaning is incomplete and that grammatical imprecisions remain (Lightbown \& Spada, 1999; Swain, 1985, 1991). As Harley (1993) and Long (1996) discussed, this is especially apparent for forms whose encodings of meaning are linguistically complex or limited in their frequency of occurrence, perceptual salience, or functional transparency. Several researchers have shown that meaning-focused content classrooms do not offer students many opportunities to produce and modify their output morphosyntactically (Swain, 1985, 1991) or to be given feedback on their grammatical accuracy (Pica, 2002; Pica \& Washburn, 2003; Pica, Washburn, Evans, \& Jo, 1998; Shah, 1999; Swain, 1991). Evidence to this effect has been found in observations and case studies of high school classes in math, history, and life science (Shah) and in descriptive studies of university-level English language courses on literature and culture (Boyd-Kletzander, 2000) and on film and culture (Pica; Pica \& Washburn; Pica et al.).

The predominant discourse in the high school classrooms was characterized by an interactional pattern in which teachers asked questions or requested information, students supplied answers, and teachers gave followup responses. Typically, the teachers responded to the students by modifying their output for them; that is, they often elaborated on students' responses without requiring the students to modify their own output. In (2), taken from a high school science class, the teacher elaborated upon the student's answer of "lemon" by adding the names of other acidic foods, commenting on them, and ending with a yes/no question. The teacher's response supplied the class with a sample of L2 forms, their functions, and their meanings. However, it failed to focus attention on the single-word answer "lemon" and encourage the students to elaborate it linguistically. Very appropriately, therefore, the teacher's question was followed up with a simple response of "yes."

(2) Teacher: It can be but sometimes we eat acids what kind of acids do we eat?

Student: Lemon.

Teacher: Very good. Lemon, vinegar, ok, oranges. So some acids happen naturally, ok? Happens in nature. Some are created when pollution moves together uh is a little bit of acid good for you?

Student: Yes.

(from Shah, 1999, cited in Pica, 2001, p. 164)

During discussion-another typical meaning-focused activity-teachers mainly provide samples of L2 input, even when negative feedback that focused on students' grammatical imprecisions might have been a more helpful response. In (3), from a university English L2 course on American culture and film, the teacher's backchannels and positive feedback during discussion of a 
review of the film Stand and Deliver (Ebert, 1990) likely sent students the message that their production was accurate, despite their many errors. (These errors are highlighted in italics.)

(3) Teacher: Give me a thumbnail sketch.

Student: One-one-one thing is, his grandmother about his grandmother? Because he feel, if he is he work hard he can go to college and he need now to pay for the aah

Teacher: Uh-huh, uh-huh.

Student: For the nursing of the- [unintelligible] the second one is, eh, the teacher give him, gives him enough time and encouraged him-like Patricia said, the teacher give him enough uh

Teacher: ah

Student: Space to let him to feel he can do good that's the most important two points for him and also he pay more attention to uh I mean the teacher pay more attention to Angel he's one of a closest students of him and he he, the teacher prevents the fighting between Angel and other students that [unintelligible] teacher if they would ask question

Teacher: Yeah yeah.

Student: He would give ninety-nine percent point.

Teacher: Yeah yeah, that's right that's right.

(Pica, 2001, p. 166)

These data reflect teachers' instructional objectives for content review, reporting, and information exchange, and they comply with the interactional norms of their lessons and discussions. As such, they reveal greater attention to the meaning of students' contributions than to their form. In the science lessons, students were asked to supply specific items in response to their teacher's content questions. On the basis of their answers, the teacher elaborated on the students' output, although the students themselves were not encouraged to do so.

In the film discussions, students were encouraged to elaborate. However, linguistic imprecisions were overlooked when they did not interfere with students' attempts to display their knowledge and convey their ideas. Although there was a good deal of negotiation for meaning, the focus of the discussion was on defining unfamiliar lexical items and clarifying factual information rather than on calling attention to grammatical errors. As the data revealed, articles and pronouns, modal verbs, and bound inflections for tense and aspect were seldom the focus of classroom negotiation. Numerous contexts for their suppliance were generated, as discussion topics required students to refer to multiple individuals, concepts, and conditions, to structure information into arguments, and to connect issues and concepts. However, the absence or imprecision of these forms was seldom acknowledged or addressed. When asked to reflect on their practice, the teachers said that they were guided by theories that emphasized meaningful, comprehensible input, language learning through communication (e.g., Shah, 1999), and wholelanguage philosophies (e.g., Boyd-Kletzander, 2000). Their responses to the 
students, they believed, were consistent with their theoretical perspectives on SLA.

The teachers' earnest intentions and theoretical grounding were offset by several concerns that remained unaddressed in their classroom practice. First, in terms of theory, the roles of output and form-focused feedback in SLA were not taken into account. As argued in the output hypothesis (Swain, 1985, 1991, 2005), meaningful input and communicative experiences need to be accompanied by opportunities for learners to produce and modify their output if they are to become more syntactically accurate. Additionally, learners need questions and feedback on imprecisions of form. Such signals challenge them to move beyond L2 development that is fluent and meaningful but filled with grammatical inaccuracies. As research has shown, it is not easy for learners to both attend to formal features of language and acquire new information in a content area (e.g., VanPatten, 1990; Wong, 2001). Second, in terms of classroom practice, the challenge of attending to formal linguistic features and acquiring new content knowledge can be especially acute when the content must be learned as a school requirement or is preferred for its inherent interest. It cannot be assumed, therefore, that learners will somehow pick up new forms-especially if the forms are barely perceptible-as they attend to content meaning. There is a need for activities, materials, and strategies that can be applied simultaneously to meet these needs. Information gap tasks, in their fundamental structure and purpose, show great promise in these areas.

With these concerns and needs in mind, a team of teachers and researchers has been working to develop form-focusing information gap tasks that provide data that are both reliable and useful to the study of SLA. Our work has been carried out primarily in meaning-focused classrooms of university and community programs for adult English language learners who have both academic and conversational needs and goals. However, we have also worked with teachers and researchers in heritage and foreign language classrooms that emphasize meaning and subject matter content in their curricula (Kang, 2006). An ongoing collaboration for task development has also been initiated with the university directors and teaching staff who developed the Language through Film course excerpted in (3).

The following sections describe three types of information gap tasks developed to serve two purposes: (a) as research treatments that encourage learners to engage in oral interaction and orient their attention toward forms whose relation to function and meaning are low in salience and therefore difficult to acquire and (b) as research tools for the collection and analysis of data on these processes. This is followed by an overview of a study on the attentional and interactional processes that were revealed as learners carried out tasks whose completion depended on low-salience forms. Data from the study are then presented to address the research questions and to show how the tasks served as a research method. 


\section{TASK DESIGN}

\section{Research Treatment}

Selection of Forms That Encode Function and Meaning. In keeping with guidelines set forth by Loschky and Bley-Vroman (1993), tasks should be designed so that the information gap requires a specific form that is essential for, or at least useful for, task completion. For example, if learners need to obtain directions to a location and must exchange information to do so, the content to fill their information gap would be phrases that include prepositions of place.

It is also necessary to choose forms that learners are developmentally ready to begin learning or are on their way to mastering, but with little progress made. Pienemann's (1981) teachability hypothesis and the principles of Harley (1993) and Long (1996), noted previously, provide a framework for form selection. Based on Pienemann, learners' readiness for forms that emerge in a syntactic sequence would be revealed through the researcher's examination of contexts for their use. Thus, a learner's readiness for features of $d o$-support that mark past time and agreement in English negation and question formation would be indicated by their emergence in $d o$-support contexts produced by the learner. Learners at the "no + verb" stage would be ready to acquire don't, but not yet ready for didn't or doesn't. For bound and free grammatical morphemes and functors that follow an accuracy order, although with considerable variability (Krashen, 1977), readiness would be indicated by the appearance of the forms in the learner's interlanguage, with suppliance of targetlike and overgeneralized versions as well as omissions in obligatory contexts for their use. In keeping with the principles of Harley and Long, good candidates would be forms that are difficult for learners to perceive in the input or that lack transparency of function or meaning. For the locations task, these could include pronouns, articles, and determiners for reference to place names as well as modal verbs to suggest direct and alternative routes.

Creating Conditions for Modified Interaction and Attention. Three types of information gap tasks appear to be especially well suited to serve as research treatments and instruments through which learners can be given modified input and feedback, produce modified output, and notice L2 forms. As such, the jigsaw (Doughty \& Pica, 1986; Pica, 1991; Pica et al., 1989; Swain \& Lapkin, 2001), spot-the-difference (Crookes \& Rulon, 1988; Long, 1980, 1981), and grammar communication (Fotos, 1994; Fotos \& Ellis, 1991; Loschky \& Bley-Vroman, 1993) tasks have been shown to promote attentional processes and interaction among learners. Because learners proceed through the same steps to reach the goals of task reconstruction and text comparison, the tasks share a similar organizational structure and goal requirement. This consistency extends both within and across the task types, as their implementation creates conditions for learners working in pairs to modify their interaction and attend to 
form, function, and meaning. The relationship between task steps and attentional and interactional processes is displayed in Table 1.

As shown in Table 1, the learners proceed in pairs through five steps for each task. Each step appears on a separate page and each learner has an individual packet of pages. At the bottom of each page, they are told to "Go to the next page and don't look back." In step 1, they read a passage based on any one of the following sources: a previously read text, a prior discussion, or a meaningful experience from an earlier session. In step 2, the learners each read a slightly different version of the original passage without revealing their respective versions to each other. The two versions differ in that each sentence is either identical to the original passage or has a phrase in which a form with low salience from the original passage appears in a different order or with a slightly different encoding. There are no truly ungrammatical phrases used in either version (i.e., formations such as a books or wented), but, rather, there are formations inconsistent with passage meaning or with the original passage read by the learners.

Table 1. Attentional and interactional processes across task steps

\begin{tabular}{|c|c|c|c|}
\hline Step & Task & $\begin{array}{l}\text { Attentional } \\
\text { processes }\end{array}$ & $\begin{array}{l}\text { Interactional } \\
\text { processes }\end{array}$ \\
\hline 1 & Read original passage. & $\mathrm{n} / \mathrm{a}$ & $\begin{array}{l}\text { Modified interaction, } \\
\text { negative feedback }\end{array}$ \\
\hline 2 & $\begin{array}{l}\text { Read version A or } \\
\text { version } B \text { of original } \\
\text { passage. }\end{array}$ & $\mathrm{n} / \mathrm{a}$ & $\begin{array}{l}\text { Modified interaction, } \\
\text { negative feedback }\end{array}$ \\
\hline 3 & $\begin{array}{l}\text { Choose between } \\
\text { sentences/among } \\
\text { phrases in versions A } \\
\text { and B. } \\
\text { Justify choices. }\end{array}$ & $\begin{array}{l}\text { Notice forms with low } \\
\text { salience as they encode } \\
\text { function, meaning. } \\
\text { Notice differences } \\
\text { between forms as they } \\
\text { encode function, } \\
\text { meaning. } \\
\text { Become aware of form, } \\
\text { function, meaning } \\
\text { relationships. }\end{array}$ & $\begin{array}{l}\text { Modified interaction, } \\
\text { negative feedback }\end{array}$ \\
\hline 4 & $\begin{array}{l}\text { Recall choices from step } \\
3 \text { and insert in cloze } \\
\text { version of original } \\
\text { passage. }\end{array}$ & $\begin{array}{l}\text { Recall form. } \\
\text { Notice the gap between } \\
\text { forms chosen and forms } \\
\text { in original passage with } \\
\text { respect to accuracy, } \\
\text { appropriateness. }\end{array}$ & $\begin{array}{l}\text { Modified interaction, } \\
\text { negative feedback }\end{array}$ \\
\hline 5 & $\begin{array}{l}\text { Compare choices with } \\
\text { original passage and } \\
\text { identify differences. }\end{array}$ & $\begin{array}{l}\text { Notice the gap between } \\
\text { needed and unneeded } \\
\text { forms. }\end{array}$ & $\begin{array}{l}\text { Modified interaction, } \\
\text { negative feedback }\end{array}$ \\
\hline
\end{tabular}


In step 3, the learners compare their passage versions aloud as they choose between the targeted phrases or between the sentences that contain the phrases and then justify their choices. For the spot-the-difference task, they choose between nearly identical sentences. In the jigsaw task, they first reorder the sentences to match the passage and then choose between them. In the grammar communication task, they choose among four nearly identical phrases, one of which has been excerpted from the original passage sentences. Before they can make their choice, they pool the two phrase options each has been given.

In step 4, without looking back at their choices or the passages they have read, the learners work together to write their chosen forms for the lowsalience items in a single cloze version of the original passage. Finally, they turn to step 5, in which they reread the original passage, compare it with their cloze version, identify any discrepancies, and posit explanations for them. Learners' participation in all five steps can activate their attentional processes for SLA. However, their participation in steps 3-5 is especially well suited to providing spoken and written data in which these processes can be identified.

Many of these attentional processes were introduced to the field of SLA by Gass (1997), Leow (1997), Robinson (1995), Schmidt, (1993), and Tomlin and Villa (1994) through the construct of noticing, a process that has been sustained, expanded, and further defined through their research and writing to date. Tomlin and Villa proposed a model of attention that included components of alertness, orientation, and detection as they pertained to the learner's access to SLA data. Alertness referred to learners' readiness to select incoming data for further processing. Their orientation directed them to particular parts of the data, and detection-referred to by others as noticing (e.g., Robinson)-registered the data in short-term memory, thereby making it available for higher levels of processing such as hypothesis formation and testing.

This view of noticing was expanded by Robinson (1995), who situated noticing in the process of awareness, through which learners encoded and retrieved L2 data for use during task-related interaction. Leow (1997) also addressed noticing in this way, defining it as the learner's awareness of new forms as they encode L2 data. Thus, according to these researchers, noticing plays a crucial role in holding on to L2 data in the short term and in making the data available for further processing over the long term. Awareness reflects a deeper understanding of its form, function, and meaning.

These perspectives on noticing and awareness are shared by Gass (1997) and Schmidt (1993, 2001), who also looked to noticing to form a link between the processing of incoming L2 data and its conversion first into input and later into intake. By extension, noticing enables learners to recognize input deviations from L2 norms or, in other words, input that differs from their current interlanguage repertoire. These occurrences, which constitute noticing the gap (see also Schmidt \& Frota, 1986), can lead learners to restructure their 
current interlanguage system. Gass further proposed apperception as an initial step that precedes noticing. Before learners notice the gap between the L2 data and their knowledge and production capability, they must first perceive and then relate the L2 data to their existing knowledge.

The importance placed on noticing and awareness has guided both the design of the current tasks and the analysis of the interaction data from their implementation. The different ways in which the tasks can draw learners' attention to the forms that encode word, phrase, and sentence function and meaning have led to further distinctions among noticing an individual form, noticing a difference between forms, noticing a discrepancy between a deviant form and its L2 counterpart, and noticing the relationship between a form and its function or meaning. Thus, in step 3 of the tasks, the need to locate, compare, and then choose between phrases and sentences sets up conditions for noticing a form as an item unto itself as well as for noticing differences among the forms that encode function and meaning in these phrases and sentences. These experiences are consistent with the views on noticing described previously. Learners might mention a form during their reading of the task passages and their choosing between passage sentences and phrases; this is a way to alert each other that they have identified the form, which is an early step toward task completion.

Learners' noticing of form has been signaled in various ways-for example, by underlining the target form in a passage (Izumi \& Bigelow, 2000), inclusion of the form in a text reconstruction activity (Izumi, 2002), reference to the target form in a learning journal (McDonough, 2005), or during thinkaloud verbal reports (Rosa \& O'Neill, 1999). However, because the current tasks require learners to interact, they provide an opportunity to study noticing of form and form differences through the learners' own verbalizations. The tasks also allow for the possibility that learners will notice the gap in the accuracy and appropriateness of the sentences they choose and those they reject. The ability of language learners to notice this gap has been investigated in the literature on recasts and includes the learners' ability to correctly identify the source of error that prompts the recasts (Mackey, Gass, \& McDonough, 2000), their ability to recognize the corrective intent of teachergenerated recasts (Nabei \& Swain, 2002), and their accuracy in immediate recall of recasts (Philp, 2003). As a result of the tasks' emphasis on interaction, as the learners deliberate over and justify their choices, they might also modify their interaction to explain and clarify their arguments and use negative feedback such as correction and recasting for what they believe are each other's incorrect choices (although none of the phrases provided to the learners were in fact ill-formed). Such verbal behavior encourages further noticing of the perceptual features of a particular form and builds awareness of its relation to function and meaning, which contributes to the internalization process. This noticing of form, function, or meaning is related to Rosa and O'Neill's awareness at the level of understanding, defined as the learners' articulation of rules that govern a targeted structure during think-aloud 
verbal reports. Thus, as the learners notice the gap between correct and incorrect form uses and indicate awareness of form in relation to function and meaning, they demonstrate further processing of the form and a readiness for its recall in the next task step.

In step 4, as the learners recall and write their choices in a single cloze version of the original passage, they are given opportunities for modified interaction and negative feedback because mutual comprehension and agreement are necessary. With respect to attention, this phase of the task encourages learners to recall or retrieve their earlier choices-an experience that researchers have claimed reveals further evidence for the different kinds of noticing. This is reminiscent of Robinson (2003), who determined what was noticed in terms of what the learner was able to verbally report.

Step 5, with its emphasis on comparison and explanation, provides a context for conditions such as those of step 3. However, the conditions are contingent on the degree of consistency between learners' earlier decisions about the phrases and sentences in steps 3 and 4 and the text of the original passage. If they are able to achieve a complete match, there is no need for them to do much more than acknowledge this step and conclude the task. Should discrepancies exist, the need to identify and explain them could activate interactional processes as well as attentional ones, particularly those related to noticing the gap.

The task development process is illustrated here using a review of the film Philadelphia (Renshaw, 1994); the tasks shown in this section are a subset of those used in the small-scale study of interaction and attention that will subsequently be reported. After viewing and discussion of the film, this brief passage from the longer movie review is given to learners:

"Philadelphia" opens strongly with an effective collection of city scenes. We see Andrew as a typical workaholic attorney, already living with HIV as part of his life. HIV from the outset is simply one element in Andrew's life, but not the defining element. Joe Miller is equally well-established, both at work and at home. Nevertheless, he recognizes the social similarities between being a black man and being a person with AIDS.

This passage contains numerous contexts for low-salience noun and verb forms, their functions, and their meanings. There is seldom a need to enrich such meaningful passages with low-salience forms, as contexts for them are abundant. However, the passages can occasionally be modified to streamline sentence complexity, reduce paragraph length, or eliminate allusions to experiences and concepts unfamiliar to learners and teachers.

Task directions begin with a purpose statement. For the first sample task, spot-the-difference, the statement tells the learners that they will become more accurate and precise in their speaking and writing in areas such as organizing, reporting, reviewing, and editing information. A table that displays and compares the directions for steps 1-5 is found in the Appendix. As shown, the directions were identical, with slight variations within step 3 . 
Table 2 displays the slightly different versions of the text given to the learners. The first sentence is the same as in the original passage. Differences begin with sentence 2, as highlighted. Three different sets of texts were prepared, each of which manipulated one of the following targets: articles and determin-

Table 2. Three versions of a spot-the-difference passage

Targeted structure Version A Version B

Articles and determiners

Pronouns and connectors

Verb and modal morphology
"Philadelphia" opens strongly with an effective collection of city scenes. 2. We see Andrew as a typical workaholic attorney, already living with HIV as part of his life. 3. HIV from the outset is simply one element in Andrew's life, but not a defining element. 4. Joe Miller is equally wellestablished, both at work and at this home. 5. Nevertheless, he recognizes social similarities between being a black man and being a person with AIDS.

"Philadelphia" opens strongly with an effective collection of city scenes. 2. We see Andrew as a typical workaholic attorney, already living with HIV as part of life. 3. HIV from the outset is simply one element in Andrew's life, but not the defining element. 4 . Joe Miller is equally wellestablished, both at work and at home. 5. As a result, he recognizes the social similarities between being a black man and being a person with AIDS.

"Philadelphia" opens strongly with an effective collection of city scenes. 2. We see Andrew as a typical workaholic attorney, already living with HIV as part of his life. 3. HIV from the outset must be simply one element in Andrew's life, but not the defining element. 4. Joe Miller is equally well-established, both at work and at home. 5. Nevertheless, he recognizes the social similarities between being a black man and being a person with AIDS.
"Philadelphia" opens strongly with an effective collection of city scenes. 2. We see Andrew as one typical workaholic attorney, already living with HIV as part of his life. 3. HIV from the outset is simply one element in Andrew's life, but not the defining element. 4. Joe Miller is equally wellestablished, both at work and at home. 5. Nevertheless, he recognizes the social similarities between being a black man and being a person with AIDS.

"Philadelphia" opens strongly with an effective collection of city scenes. 2. We see Andrew as a typical workaholic attorney, already living with HIV as part of his life. 3. HIV from the outset is simply one element in Andrew's life, and not the defining element. 4. Joe Miller is equally wellestablished, both at work or at home. 5. Nevertheless, he recognizes the social similarities between being a black man and being a person with AIDS.

"Philadelphia" opens strongly with an effective collection of city scenes. 2. We saw Andrew as a typical workaholic attorney, already living with HIV as part of his life. 3. HIV from the outset is simply one element in Andrew's life, but not the defining element. 4. Joe Miller was equally wellestablished, both at work and at home. 5. Nevertheless, he recognized the social similarities between being a black man and being a person with AIDS.

Note. Differences are highlighted in the passages for the sake of illustration. However, these forms were not highlighted or in any way marked in the versions given to students.

Source. Excerpt based on Renshaw, 1994. 
ers, pronouns and connectors, or verb and modal morphology. Each pair of learners worked through only one version (i.e., targeting articles and determiners, pronouns and connectors, or verb and modal morphology) of each task (i.e., jigsaw, spot-the-difference, grammar communication). For the spotthe-difference task, for example, pairs 1 and 2 carried out the article and determiner version, whereas pairs 3 and 4 carried out the version for connectors and pairs 5 and 6 completed the version for modals and verbal morphology. During the following session, all groups completed a jigsaw task: Pairs 1 and 2 carried out the version for verbs, pairs 3 and 4 did the version for articles and determiners, and pairs 5 and 6 completed the version for connectors. As mentioned previously, there are no truly ungrammatical phrases used in either version, only formations that are inconsistent with passage meaning or with the original passage read by the learners.

Table 3 displays the passages given to the learners in steps 4 and 5 . In step 4, learners are given the cloze version of the original passage and must complete the task together. In the final step, learners are given the original passage with the items that had been excerpted in the cloze passage underlined and they compare this version with the cloze passage that they completed in step 4.

Both the jigsaw and grammar communication tasks ask learners to follow a set of directions very similar to those of the spot-the-difference task. Learners are instructed to choose between phrases that contain the forms they need to learn, justify their choices, recall them in a cloze activity, and then compare their cloze version with the original passage and explain any differences that they find. To maintain authenticity, the purpose statement given for the

Table 3. Passages for steps 4 and 5 for articles and determiners

\begin{tabular}{|c|c|c|}
\hline Step & Version & Passage \\
\hline 4 & Cloze & $\begin{array}{l}\text { "Philadelphia" opens strongly with an effective collection of } \\
\text { city scenes. } 2 \text {. We see Andrew as } \\
\text { living with HIV as part of his life. } 3 \text {. HIV from the outset is sim- } \\
\text { ply one element in Andrew's life, but not } \\
\text { Joe Miller is equally well-established, both at work and at } \\
.5 \text {. Nevertheless, he recognizes } \\
\text { between being a black man and being a person with AIDS. }\end{array}$ \\
\hline 5 & Original & $\begin{array}{l}\text { "Philadelphia" opens strongly with an effective collection of } \\
\text { city scenes. } 2 \text {. We see Andrew as a typical workaholic attorney, } \\
\text { already living with HIV as part of his life. } 3 \text {. HIV from the outset } \\
\text { is simply one element in Andrew's life, but not the defining ele- } \\
\text { ment. } 4 \text {. Joe Miller is equally well-established, both at work and } \\
\text { at home. } 5 \text {. Nevertheless, he recognizes the social similarities } \\
\text { between being a black man and being a person with AIDS. }\end{array}$ \\
\hline
\end{tabular}


jigsaw task tells the learners that the task will help them organize information, whereas for the grammar communication task, they are told that they will be helped to report information accurately.

For the jigsaw task, each member of the participant pair is provided with an unordered set of individual sentences; each set contains some sentences taken directly from the original passage and others that have been modified (as illustrated for the spot-the-difference task). Using the sentences provided, learners are asked to carry out the choosing step (step 3) in two parts. First, they are to choose the order of individual sentences as they appeared in the original passage. Then they are to choose the version of each sentence that they recall from the original movie review passage, much as they did for spotthe-difference. These two components of choosing are designed to activate slightly different attentional processes. When choosing sentence order, the learner's noticing of forms, form differences, and gaps is incidental to the choice; in choosing between different sentences, such noticing is implicit but nonetheless more directly related to the choice. Versions A and B of a sample passage are shown in Table 4 . Their sentences differ slightly in articles and determiners.

In the grammar communication task, learners again follow directions that are nearly identical to those of spot-the-difference. However, in this case they choose among phrases that contain specific forms or features for cloze reconstruction of the review passage. Table 5 illustrates Versions A and B of a grammar communication task.

Table 4. Jigsaw passage versions for articles and determiners

$\begin{array}{ll}\text { Version A } & \text { Version B }\end{array}$

Sentence 1 "Philadelphia" opens strongly with an effective collection of city scenes.

Sentence Joe Miller is equally wellestablished, both at work and at his home.

Sentence We see Andrew as a typical workaholic attorney, already living with HIV as part of his life.

Sentence Nevertheless, he recognizes the social similarities between being a black man and being a person with AIDS.

Sentence ___ HIV from the outset is simply one element in Andrew's life, but not the defining element.
Sentence 1 "Philadelphia" opens strongly with an effective collection of city scenes.

Sentence ___ Joe Miller is equally wellestablished, both at work and at home.

Sentence We see Andrew as one typical workaholic attorney, already living with HIV as part of his life.

Sentence ___ Nevertheless, he recognizes social similarities between being a black man and being a person with AIDS.

Sentence HIV from the outset is simply one element in Andrew's life, but not a defining element. 
Table 5. Grammar communication task for articles and determiners

\begin{tabular}{|c|c|}
\hline Version A & Version B \\
\hline $\begin{array}{l}\text { "Philadelphia" opens strongly with an } \\
\text { effective collection of city scenes. } 2 \text {. } \\
\text { We see Andrew as }\end{array}$ & $\begin{array}{l}\text { "Philadelphia" opens strongly with an } \\
\text { effective collection of city scenes. } 2 \text {. } \\
\text { We see Andrew as }\end{array}$ \\
\hline $\begin{array}{l}\text { a typical workaholic attorney } \\
\text { the typical workaholic attorney } \\
\text { already living with HIV as part of his } \\
\text { life. } 3 \text {. HIV from the outset is simply } \\
\text { one element in Andrew's life, but not }\end{array}$ & $\begin{array}{l}\text { one typical workaholic attorney } \\
\text { his typical workaholic attorney } \\
\text { already living with HIV as part of his } \\
\text { life. 3. HIV from the outset is simply } \\
\text { one element in Andrew's life, but not }\end{array}$ \\
\hline $\begin{array}{l}\text { his defining element } \\
\text { its defining element } \\
\text { 4. Joe Miller is equally well- } \\
\text { established, both at work and at }\end{array}$ & $\begin{array}{l}\text { a defining element } \\
\text { the defining element } \\
\text { 4. Joe Miller is equally well- } \\
\text { established, both at work and at }\end{array}$ \\
\hline $\begin{array}{l}\text { home } \\
\text { the home } \\
\text { 5. Nevertheless, he recognizes }\end{array}$ & $\begin{array}{l}\text { his home } \\
\text { this home } \\
\text { 5. Nevertheless, he recognizes }\end{array}$ \\
\hline $\begin{array}{l}\text { their social similarities } \\
\text { social similarities } \\
\text { between being a black man and being } \\
\text { a person with AIDS. }\end{array}$ & $\begin{array}{l}\text { these social similarities } \\
\text { the social similarities } \\
\text { between being a black man and being } \\
\text { a person with AIDS. }\end{array}$ \\
\hline
\end{tabular}

\section{Developing Tools for Data Collection}

In designing tasks as research instruments on learner interaction in SLA, care must be given to ensure that a large amount of data can be collected and that the data will be a valid representation of learners' interactions and their attention to the relationships of form, function, and meaning that need to be further developed. The materials as well as their instructions and maintenance need to satisfy researchers' goals for both immediate data collection and eventual application to SLA theory. If these materials are to be used longitudinally in a classroom environment, task instructions need to be straightforward, to allow students to carry them out without continuous involvement of their teacher. Teacher and researcher involvement in design, piloting, and revision of the tasks and the writing of instructions is essential to the success of this effort. Consistency across task instructions is of paramount importance if the data are to be pooled for later analysis.

Access to the different task types ensures that learners can work on multiple forms, their functions, and their meanings, and it provides researchers with ample data for analysis. In a given week, learners might engage in a 
meaning-focused activity, such as a discussion, during their first session and then spend the following days reading a text passage based on the discussion and completing its companion spot-the-difference task. In a subsequent session, learners might read and discuss a different passage and, finally, complete its companion jigsaw or grammar communication task.

Learners often tend to work independently, and it is important to gather data on their oral interactions and displays of attention even during those times. The tasks do this in several ways. First, learners are not allowed to show each other their passage versions, so oral interaction is ensured as they make their choices and justify their answers. Second, they are asked to share the same page to complete the cloze step of the task, which again ensures against parallel private work. Finally, they are asked to write both their responses to the cloze passage and their identification of differences between their choices and those of the original passage. Although this precaution limits the speaking requirement, the written responses provide a record for further analysis.

\section{Instrument for Data Analysis}

If a task is designed to activate attention to form, function, and meaning and to require spoken and written interaction throughout its implementation, it can yield a rich source of data for analysis of the relationship of attentional and interactional processes as they bear on SLA. Such data also eliminate or greatly reduce the need to rely on follow-up interviews or introspective data for insight into attentional processes.

Attentional Processes. Operationalization of attentional processes is necessary in accounting for the data. Noticing, for example, can be operationalized in several ways: (a) Simple noticing of form is characterized by learners' segmentation of a targeted form in isolation or in the word or phrase in which it appears in a passage; (b) to be categorized as noticing the difference, learners must segment, or extract, both their own and each other's form; (c) for noticing the gap, they must offer a positive or negative value judgment about their own or each other's form, phrase, or sentence, or between these and their counterparts in the original passage-indicating, for example, that one item is wrong or another is better (this evaluation feature is necessary because, as learners who produce interlanguage talk, they are not likely to provide a fully targetlike version of the form, phrase, or sentence that they have identified as the more accurate one); (d) noticing form, function, and meaning relationships, characteristic of awareness, is operationalized through learners' references to these relationships either in themselves or with respect to a meaning-focused experience, such as an earlier discussion; and (e) recall is characterized in terms of oral or written responses to the cloze passage as well as utterances with metalanguage that refer to memory processes, such 
as "I remember that." To be coded as recall, the utterance must be made when the passages in which the forms appeared are not accessible. Thus, in our operationalization of recall, this attentional process is most likely to occur when learners complete the cloze task (step 4). Participants might recall the form, function, or meaning of a targeted item, or any combination of these aspects. Such distinctions should be noted when analyzing the data.

Interactional Processes. It is also important to operationally define those interactional processes that relate to SLA, which include modified interaction, which involves negotiation and responses of adjusted output. Among them would be simple signals as well as signal and response utterances that syntacticize or semantically adjust previous utterances that contained the forms on which the learners needed to focus their attention. Also important are explicit correction and recasting. Read recasts can occur as a result of one pair member simply reading an alternate version of a sentence in a passage, which happened, fortuitously, to follow the other member's erroneous one. Pair-generated recasts can occur during any of the task steps, as one pair member recodes the other's nontarget use of a form with low salience while maintaining utterance meaning.

As illustrated in Table 1, interactional processes that relate to targeted forms can occur throughout task implementation. Attentional processes can be activated throughout the tasks, although noticing is more likely to occur in step 3 , as learners choose between answers. Similarly, awareness of form, function, and meaning connections is more likely to arise as learners justify their choices in step 3. However, such awareness can also occur as they recall their choices during cloze passage completion in step 4. Although not fully tested under multiple conditions for SLA, this model of task-based interaction and attention allows for initial description and analysis of data gathered from task implementation. It is to a small-scale, descriptive study of implementation that we now turn.

\section{TASK IMPLEMENTATION: A STUDY OF INTERACTION AND ATTENTION TO FORM IN A MEANING-FOCUSED CLASSROOM}

This section summarizes a study undertaken in light of concerns about learners' need to attend to forms with low salience in their meaning-focused classrooms. It aims to provide a description of the ways in which learner interaction during tasks based on classroom texts might meet these attentional needs. Thus, the study offers a way to address broad issues of attention to relationships of form, function, and meaning in SLA and to test the tasks as research treatments and instruments for data collection and analysis.

There was one overarching question: What does the way that learners interact during tasks whose completion depends on forms with low salience reveal about their attention to these forms? This was followed by three research ques- 
tions: (a) How does learners' task implementation assist their attention to these forms? Which attentional processes are assisted? (b) How does task implementation promote modified interaction for SLA? Which interactional processes are promoted? (c) Is there a relationship between these attentional and interactional features? Also of interest was whether there were differences among the tasks in the extent to which their implementation drew attention to the forms, their functions, and their meanings.

\section{Method}

Participants. The participants were 12 adult intermediate-level learners of English, with first language (L1) backgrounds of Korean, Mandarin, and Taiwanese, enrolled in a short-term intensive course-English through Film-in which information gap tasks were a crucial component. These 10 female and 2 male participants had at least 6 years of prior formal instruction in English and an average residence of 4 years in the United States.

To make sure that each participant had not yet mastered the forms that had been observed to give them trouble during classroom interaction, they were engaged in semistructured interviews and e-mail exchanges. The forms that were identified as problematic (i.e., articles, determiners, pronouns, connectors, modal verbs, and verb inflections) were consistent with those targeted by the tasks. The learners' omissions, substitutions, and inconsistencies in the use of the forms during interviews and in e-mails established that they had some degree of control over the forms because they emerged in the learners' interlanguage with varying degrees of accuracy. Their intermediate proficiency together with their history of L2 instruction and exposure also served as preliminary indicators of their developmental readiness to advance in the acquisition of these forms. Given that the present study focused on questions of attention and interaction for SLA, the participants appeared to be suitable. Follow-up studies regarding these learners' development and their acquisition of targetlike features would require much more documentation of their readiness and motivation.

Procedure. The study took place over 5 days. Data were collected during the task-based portion (the last 3 days). On days 1 and 2, participants and their teacher watched Philadelphia, engaged in comprehension exercises, and discussed the characters, story line, and theme. Medical and legal terminology was defined and explained as an aid to film comprehension. At no point during the study or course were participants given instruction on the lowsalience forms targeted by the tasks.

Prior to the first information gap task, the L2 learners were randomly organized into pairs, which remained intact for the study. Following initial instructions by the teacher, the pairs carried out each of the three information gap 
tasks: grammar communication on day 3 , spot-the-difference on day $4,{ }^{1}$ and jigsaw on day 5 . To avoid disrupting the flow of interaction during the tasks, the teacher intervened only when learners solicited clarification or support. All interaction was tape-recorded and later transcribed. The pairs also wrote their answers to the cloze step of each task. These answers provided data about whether the learners were able to recall the items they had read and chosen during steps 1-3.

Tasks. Each of three task types was created using passages taken from three different reviews (Brenner, n.d.; J. Ellis, n.d.; Hicks, 1994) of the movie Philadelphia (Demme, 1993). All review passages already contained numerous examples of the targeted low-salience forms. As a result, they needed only minor modification, mainly to ensure uniformity of length (13 sentences). Three versions of each passage were created to accommodate the three different form categories: one for articles and determiners, another for pronouns and connectors, and another for verb features. A second goal was to gather a large amount of data on the different forms in the passages.

Data were gathered from each of the three versions of each task type (grammar communication, spot-the-difference, and jigsaw). This range allowed the researchers to study task implementation and classroom compatibility and to track attentional and interactional processes associated with low-salience features across the tasks. Thus, for example, on day 3 , all six pairs read the same passage for the grammar communication task, but pairs 1 and 2 completed the version whose passages were modified for articles and determiners, pairs 3 and 4 completed the version modified for pronouns and connectors, and pairs 5 and 6 completed the version modified for verb endings and modals. The implementation of tasks is shown in Table 6 .

\section{Results and Discussion}

Jigsaw, spot-the-difference, and grammar communication task findings for all pairs of participants are shown in Tables 7 and 8. The attentional processes (Table 7) and the interactional processes (Table 8) are broken down by specific process, task type, and step (3-5). For steps 3-5, these tables present token counts and percentages of the sentence or phrase decisions the six pairs needed to make in choosing, recalling, and comparing the forms of the 12 sentences in their task passages. Therefore, the base number used for determining the percentage scores for each step was 72 for the jigsaw and grammar communication sentences. Because only five of the pairs recorded their spotthe-difference implementation, their number of decisions was 60 . The percentage distribution of attentional and interactional processes for each step are displayed in Figures 1-3. The data were coded by the researchers for these attentional and interactional features. Interrater reliability was .95 for atten- 
Table 6. Task implementation matrix

\begin{tabular}{|c|c|c|c|c|}
\hline & Days 1-2 & Day 3 & Day 4 & Day 5 \\
\hline Pairs & & $\begin{array}{c}\text { Grammar } \\
\text { communication } \\
\text { task }\end{array}$ & $\begin{array}{l}\text { Spot-the- } \\
\text { difference } \\
\text { task }\end{array}$ & $\begin{array}{l}\text { Jigsaw } \\
\text { task }\end{array}$ \\
\hline $\begin{array}{l}1 \\
2\end{array}$ & & Articles, Determiners & $\begin{array}{l}\text { Verb morphology, } \\
\text { Modals }\end{array}$ & Pronouns, Connectors \\
\hline 3 & $\begin{array}{l}\text { For all } \\
\text { pairs, } \\
\text { watch }\end{array}$ & Pronouns, Connectors & Pronouns, Connectors ${ }^{a}$ & $\begin{array}{l}\text { Verb morphology, } \\
\text { Modals }\end{array}$ \\
\hline 4 & $\begin{array}{l}\text { film; read } \\
\text { reviews; } \\
\text { discuss }\end{array}$ & Pronouns, Connectors & $\begin{array}{l}\text { Verb morphology, } \\
\text { Modals }^{\text {a }}\end{array}$ & $\begin{array}{l}\text { Verb morphology, } \\
\text { Modals }\end{array}$ \\
\hline $\begin{array}{l}5 \\
6\end{array}$ & & $\begin{array}{l}\text { Verb morphology, } \\
\text { Modals }\end{array}$ & Pronouns, Connectors & Articles, Determiners \\
\hline
\end{tabular}

aA printing error on the articles and determiners version of the spot-the-difference task resulted in a last-minute substitution.

tional features, .91 for interactional features, and .99 for recall scoring. Steps 1 and 2, which involved silent reading, did not allow for collection, coding, or analysis of attentional or interactional data.

The first research question asked about the ways in which the learners' task implementation assisted their attention to forms with low salience. First,

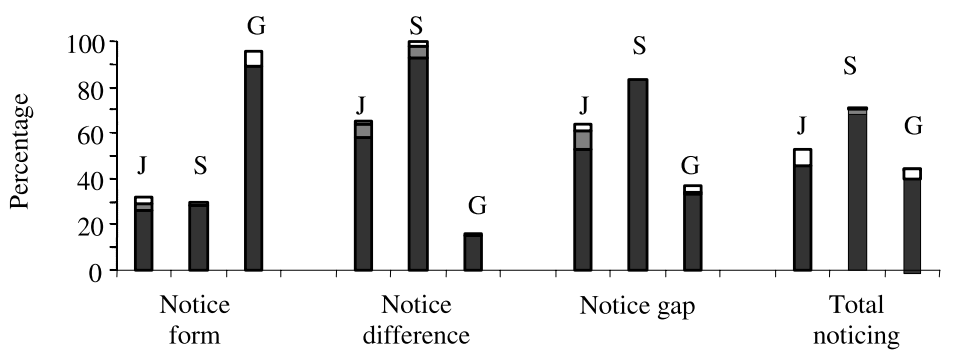

$\square$ Step 3ロStep 4ロStep 5

Figure 1. Distributions of attentional processes in pairwork decisions across task steps in jigsaw (J), spot-the-difference (S), and grammar communication (G) tasks. 
as revealed in Table 7 and displayed in Figure 1, each task engaged the pairs in the three noticing processes that were totaled to give a score for total noticing. As shown in the "Total" column, there were 116, 128, and 108 decisions that involved the passage sentences and phrases in which the forms were noticed for the jigsaw, spot-the-difference, and grammar communication tasks, respectively. This reflects the fact that making a decision in choosing, recalling, or comparing sentences often featured two or more noticing processes. As displayed in Figure 1, noticing was especially prominent during step 3, the step that required a choice. Thus, $85 \%$ of the pairs' total noticing occurred during step 3 for the jigsaw task, $96 \%$ for the spot-the-difference task, and $92 \%$ for the grammar communication tasks. ${ }^{2}$ These multiple applications of noticing suggested that for these learners, noticing consisted of orientations that

Table 7. Frequencies and distribution of attentional processes used in sentence and phrase decisions across task steps

\begin{tabular}{|c|c|c|c|c|c|c|c|}
\hline \multirow[b]{3}{*}{ Attentional processes } & \multicolumn{6}{|c|}{ Steps } & \multirow{3}{*}{$\begin{array}{c}\text { Total }^{\mathrm{a}} \\
n\end{array}$} \\
\hline & \multicolumn{2}{|c|}{3} & \multicolumn{2}{|c|}{4} & \multicolumn{2}{|c|}{5} & \\
\hline & $n$ & $\%$ & $n$ & $\%$ & $n$ & $\%$ & \\
\hline \multicolumn{8}{|l|}{ Notice form } \\
\hline Jigsaw & 19 & 26 & 2 & 3 & 2 & 3 & 23 \\
\hline Spot-the-difference & 17 & 28 & 1 & 2 & 0 & 0 & 18 \\
\hline Grammar communication & 64 & 89 & 0 & 0 & 5 & 7 & 69 \\
\hline \multicolumn{8}{|l|}{ Notice differences } \\
\hline Jigsaw & 42 & 58 & 4 & 6 & 1 & 1 & 47 \\
\hline Spot-the-difference & 56 & 93 & 3 & 5 & 1 & 2 & 60 \\
\hline Grammar communication & 11 & 15 & 0 & 0 & 1 & 1 & 12 \\
\hline \multicolumn{8}{|l|}{ Notice gap } \\
\hline Jigsaw & 38 & 53 & 6 & 8 & 2 & 3 & 46 \\
\hline Spot-the-difference & 50 & 83 & 0 & 0 & 0 & 0 & 50 \\
\hline Grammar communication & 24 & 33 & 1 & 1 & 2 & 3 & 27 \\
\hline \multicolumn{8}{|l|}{ Total noticing } \\
\hline Jigsaw & 99 & 46 & 12 & 17 & 5 & 7 & 116 \\
\hline Spot-the-difference & 123 & 68 & 4 & 2.5 & 1 & 0.5 & 128 \\
\hline Grammar communication & 99 & 46 & 1 & 0.5 & 8 & 4 & 108 \\
\hline \multicolumn{8}{|l|}{ Reveal awareness } \\
\hline Jigsaw & 12 & 16 & 7 & 10 & 1 & 1 & 20 \\
\hline Spot-the-difference & 10 & 17 & 9 & 15 & 3 & 5 & 22 \\
\hline Grammar communication & 23 & 32 & 2 & 3 & 3 & 4 & 28 \\
\hline \multicolumn{8}{|l|}{ Recall } \\
\hline Jigsaw & - & - & 64 & 89 & 0 & 0 & 67 \\
\hline Spot-the-difference & - & - & 58 & 97 & 0 & 0 & 56 \\
\hline Grammar communication & - & - & 58 & 82 & 0 & 0 & 58 \\
\hline
\end{tabular}

${ }^{\mathrm{a}}$ Total refers to the total attentional processes used in sentence and phrase decisions. 
ranged from simple perception to more articulated identification of differences and evaluations of accuracy.

The consistency across percentages for step 3 was offset somewhat by distributional differences in attentional processes. These differences are illustrated in Figure 1. During the jigsaw task, $58 \%$ of the sentences were noticed with respect to their differences and $53 \%$ were noticed for their gaps. These percentages-at $93 \%$ and $83 \%$-were also high on the spot-the-difference task. The figures for noticing during step 3 were much lower for the grammar communication task, as the pairs displayed noticing of differences for only $15 \%$ of their sentences and noticing the gap for $33 \%$. On the other hand, simple noticing, which occurred with $89 \%$ of the sentences on the grammar communication task, was much more apparent.

Differences in the distribution of noticing in the grammar communication task compared to the jigsaw and spot-the-difference tasks might have been related to the number and format of options for choosing. During the grammar communication task, pair members had four phrases from which to choose. They tended to present each other with the phrases and announce their decisions. In the jigsaw and spot-the-difference tasks, the pair members had to choose between two sentences. This set up a basis for comparison, commentary, and evaluation.

Figure 2, which displays the distribution of awareness across task steps (labeled "reveal awareness" in Table 7), shows that all six pairs revealed awareness of the forms, their functions, and their meanings during at least one of the steps. They made 12 sentence decisions in which they revealed awareness during step 3 on the jigsaw task. Although this means that learners showed awareness on only $16 \%$ of all sentences in this task, it is notable that this constituted $60 \%$ of the pairs' awareness that was distributed across steps $3-5$. During the recall step (step 4), 35\% of the total evidence for awareness

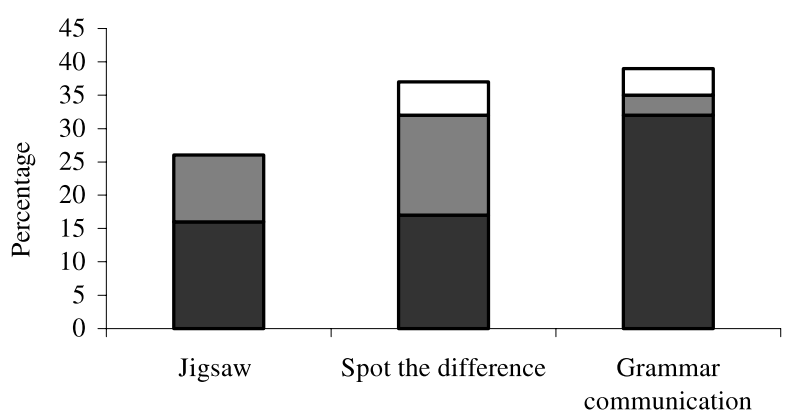

$\square$ Step $3 \square$ Step $4 \square$ Step 5

Figure 2. Distributions of awareness in pairwork decisions across task steps. 
was found; this was revealed as the pairs deliberated over the items that they had chosen. However, instances of awareness were negligible during the comparison step. This pattern of awareness was consistent across the spot-thedifference task as well, with a distribution of $45 \%$ of all examples of awareness at step 3,40\% at step 4, and 5\% at step 5. For the grammar communication task, awareness was revealed primarily during the choose step (step 3), as the pairs commented on relationships of form, function, and meaning for $32 \%$ of their sentences decisions. However, it was negligible during the recall and comparison steps.

Across the tasks, all pairs were able to recall phrases with the targeted forms from the sentences of passages they had read in steps 1 and 2 and chosen in step 3. This was revealed during their spoken decisions and written responses to the cloze passage of step 4. On the jigsaw and spot-thedifference tasks, the pairs were able to recall $89 \%$ and $97 \%$ of the phrases with nonsalient forms. For the grammar communication task, this figure was $82 \%$. There was a strong relationship between noticing a form as encoded in the passages of step 3 and recalling it while completing a cloze version of these passages in step 4 . Thus, of the 64 phrases that were recalled during the cloze portion of the jigsaw task, $81 \%$ had been noticed during step 3. These figures were $95 \%$ for the phrases recalled for spot-the-difference and $81 \%$ for those of grammar communication. Although some of the noticed forms were not recalled, their frequency and percentages were much lower than those that were recalled. Thus, on the jigsaw task, seven of the forms that had been noticed in step 3 were not recalled in step 4 . This accounted for only $8 \%$ of the noticed forms, however. Similar patterns were found for the spot-the-difference task. Only two of the forms that had been noticed in step 3 were not recalled in step 4 . This figure was somewhat higher for the grammar communication task, as $13 \%$ or $18 \%$ of the noticed forms were not recalled in step 4.

The second research question asked about the ways in which task implementation promoted interactional processes that have been shown to assist SLA. Findings are displayed in Figure 3 and Table 8. During the jigsaw task, all six pairs of participants often modified their interactions through negotiation signals and responses of modified output, doing so as they made $76 \%$ of their decisions during the choose step and as they recalled $42 \%$ of them during the cloze step. Modified interaction occurred throughout the steps of the grammar communication task as well. However, there was less overall modified interaction than in the jigsaw task and slightly more modified interaction during the recall step than during the choose step. These figures were $39 \%$ and $46 \%$, respectively.

These differences in the choose step appeared to be related to its different demands. The fill-in format in each sentence and the four phrase options of the grammar communication task might have enabled the pairs to hone in on a preferred form. The pairs were not required to either reorder sentences or 


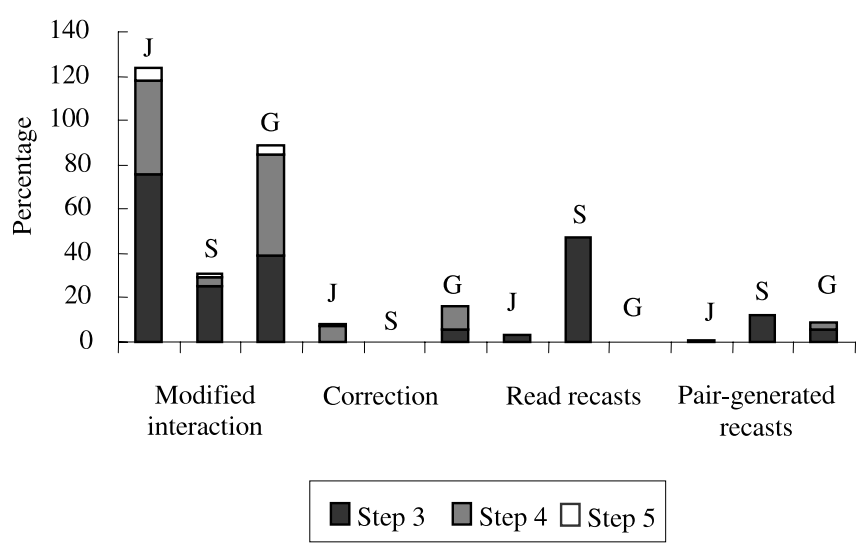

Figure 3. Distributions of interactional processes in pairwork decisions across task steps in jigsaw (J), spot-the-difference (S), and grammar communication (G) tasks.

hunt down subtle differences between the two versions of each sentence, as they were asked to do in the jigsaw task. A further reason for this difference in interactional processes is that the jigsaw task gave the pairs two ways to choose. They were asked to choose the order of their sentences and, after that, to choose the sentence that they thought was better. However, as the pairs chose their order, they would often stop and choose between the two versions, reminding each other that this step was to be taken after the ordering but, nonetheless, pausing to choose between the versions. An example of this sort of modified interaction is shown in (4), in which a L1 Chinese learner (A) and a L1 Korean learner (B) work on the task:

(4) A: Uh. The sentence four. Charles Wheeler, the firm, firm's senior partner assigns Andrew a case that involves their most important client.

B: Yeah. I think that. But my sentence is, Charles Wheeler, the firm's senior partner assigns Andrew a case that must involve. I think must should be omitted. Must. Not must involve.

A: Must? [Syntactically modified negotiation signal]

B: Yeah, must. My sentence is must involve, but I don't think so. [Notice the gap/ Syntactically modified response]

A: Yeah.

B: Just involve. [Notice form/Syntactically modified negotiation signal]

A: Yeah.

During the spot-the-difference task, the pairs engaged in modified interaction for $25 \%$ of their sentences during their choose step, but only $4 \%$ during the recall step. On the other hand, it was during the choosing step that they recasted 28 of their sentence choices as they read their pas- 
Table 8. Frequencies and distribution of interactional processes used in sentence and phrase decisions across task steps

\begin{tabular}{|c|c|c|c|c|c|c|c|}
\hline \multirow[b]{3}{*}{ Interactional processes } & \multicolumn{6}{|c|}{ Steps } & \multirow{3}{*}{$\begin{array}{c}\text { Total } \\
n\end{array}$} \\
\hline & \multicolumn{2}{|c|}{3} & \multicolumn{2}{|c|}{4} & \multicolumn{2}{|c|}{5} & \\
\hline & $n$ & $\%$ & $n$ & $\%$ & $n$ & $\%$ & \\
\hline \multicolumn{8}{|l|}{ Modified interaction } \\
\hline Jigsaw & 55 & 76 & 30 & 42 & 4 & 6 & 89 \\
\hline Spot-the-difference & 15 & 25 & 2 & 4 & 1 & 2 & 18 \\
\hline Grammar communication & 28 & 39 & 33 & 46 & 3 & 4 & 64 \\
\hline \multicolumn{8}{|l|}{ Correction } \\
\hline Jigsaw & 0 & 0 & 5 & 7 & 1 & 1 & 6 \\
\hline Spot-the-difference & 0 & 0 & 0 & 0 & 0 & 0 & 0 \\
\hline Grammar communication & 4 & 6 & 7 & 10 & 0 & 0 & 11 \\
\hline \multicolumn{8}{|l|}{ Read recasts } \\
\hline Jigsaw & 6 & 3 & 0 & 0 & 0 & 0 & 6 \\
\hline Spot-the-difference & 28 & 47 & 0 & 0 & 0 & 0 & 28 \\
\hline Grammar communication & 0 & 0 & 0 & 0 & 0 & 0 & 0 \\
\hline \multicolumn{8}{|l|}{ Pair-generated recasts } \\
\hline Jigsaw & 0 & 0 & 1 & 1 & 0 & 0 & 1 \\
\hline Spot-the-difference & 7 & 12 & 0 & 0 & 0 & 0 & 7 \\
\hline Grammar communication & 4 & 6 & 2 & 3 & 0 & 0 & 6 \\
\hline
\end{tabular}

${ }^{\text {a }}$ Total refers to the total interactional processes used in sentence and phrase decisions.

sage versions to each other. These read recasts were $47 \%$ of their choices. Yet another seven of their sentence choices were produced during pairgenerated responses. There was minimal recasting by the pairs on the two other tasks. The emphasis on recasting in spot-the-difference might have been task-specific. The layout of the sentences during step 3 of this task was a paragraph, whereas the sentences were listed in a scrambled order for the jigsaw task, and they were interrupted by blank lines with choices beneath in the grammar communication task. The paragraph format might have lent itself more to reading as a way for the pairs to keep track of their choices or by association with the passage reading they had just completed for steps 1 and 2.

Correction, although low in frequency of occurrence, was provided by all six pairs during only two steps of the task, and mainly during the recall step. The low amount of correction might have been related to an absence of truly ungrammatical phrases in either of their versions. As mentioned previously, formations such as a books or wented were not used to encode erroneous phrases, but, rather, forms were employed that were inconsistent with passage meaning or with the original passage read by the learners. 
The third research question asked about attentional and interactional relationships. As noted throughout the previous findings, most of the attentional and interactional activity occurred during the choose step. Although noticing processes, modified interaction, and recasting differed in their distribution, overall, for this step, there was a strong relationship between noticing forms with low salience and interactional processes claimed to assist SLA. The correlation was .62 using Pearson's $r(p<.05)$. Despite the overall correlation across the three tasks, relationships between noticing and interaction were more prominent during the jigsaw and spot-the-difference tasks. Thus, of the 72 sentence choices that the pairs made for jigsaw, $81 \%$ of those that revealed simple noticing or noticing of differences or gaps were encoded in negotiation signals, modified responses, corrections, or recasts. These interactional features constituted $82 \%$ of the 60 decisions made during step 3 for the spotthe-difference task

However, these noticing and interactional processes were revealed together in only $45 \%$ of the 72 decisions for the grammar communication task. This might have been yet another reflection of task format, as the straightforward, familiar, fill-in-the-blank layout of the task drew the pairs to notice the phrases placed below each blank. This might also have reduced their need to modify their interaction toward mutual understanding. Additionally, task sequence might have contributed to this pattern. Grammar communication was the first of the three tasks in which the pairs engaged. It is possible that they might not have anticipated the precision that the subsequent cloze step required.

These noticing through interaction connections appeared to assist the pairs' accurate recall of phrases from step 3. Thus, 74\% of the phrases recalled for the jigsaw task and $80 \%$ of those for the spot-the-difference task had been both noticed and encoded in an interactional process during the preceding choose step. On the other hand, only $35 \%$ of the recalled grammar communication choices had been noticed and encoded in this way. Of particular note was the finding that those choices made within the context of recasts-which predominated in the spot-the-difference task-were recalled more accurately than those that were accompanied by modified interaction-the dominant mode of the jigsaw task-and that both interactional processes were connected with high recall percentage scores. Thus, scores of $89 \%$ on the jigsaw and $97 \%$ on the spot-the-difference tasks suggest that the pairs applied interaction moves judiciously as needed during their task implementation.

The pairs' success with recall for the grammar communication task appeared to rely on simple noticing of forms in phrases, attesting again to the relative simplicity of the task layout and presentation of phrase options. The other two tasks activated a greater frequency and variety of interactional and attentional processes. Not only did the pairs achieve higher recall scores, but they also had more opportunities to notice crucial perceptual differences in the low-salience forms with which they clearly needed help. 


\section{CONCLUDING COMMENTS}

The success of information gap tasks as classroom activities and research instruments has been well established by their long-standing presence in professional references, classroom textbooks, and SLA research. The findings of this small-scale, descriptive study suggest additional roles for these tasks. As the study revealed, the tasks can offer a classroom-based methodology for the study of attention and interaction in SLA. As instructional treatments that can help learners acquire and use low-salience L2 forms that have shown little development over time, they allow for the study of long-term SLA as well. Observations of discussions and lessons-the two formats that typify meaningfocused classrooms-revealed that students' omissions and misapplications of such forms were seldom acknowledged by their teachers, nor were they noted by the students (Pica, 2002). Notably missing were activities that would draw attention to these forms but preserve the overall focus of the content curriculum. Because information gap tasks had already been shown to promote attention to message form in the interest of achieving precision in message exchange and goal attainment, we believed they would be good candidates for form focus. Our resultant jigsaw, spot-the-difference, and grammar communication tasks, although somewhat different in their goals, nevertheless shared attention-promoting features that made them useful. They could be adjusted to target the forms that the students needed, activate interaction and correction, and provide authenticity and variety in the classroom.

These connections across task, attention, and interaction in relation to L2 form, function, and meaning are represented in the following examples, in which a pair of learners engaged in modified interaction to choose, recall, and compare the forms that encoded the meaning of sentences in their texts. At the same time, the pairs revealed processes of noticing the form itself and in comparison with its very close counterpart. Discussion of their choices revealed awareness of the functions of the forms and the meanings they encoded.

When asked to locate differences and choose between sentences, the learners extracted and referred to phrases in ways that suggested noticing and awareness of form, function, and meaning. These processes are revealed in (5) and (6), which show modified interaction produced during step 3 of a spotthe-difference task. The passage being discussed is given as Table 9 .

(5) A: Yeah, so next one. Certain that he has been fired because of his illness or his gayness or both, Hanks decides to go after the firm with a discrimination suit, even as his body is starting to give out.

B: Even...

A: As. [Noticing the difference]

B: Ok. Certain that he has been fired because of his illness or his gayness or both, Hanks decide to go after the firm with a discrimination suit, even though his body starting to give out. 
Table 9. Spot-the-difference task passages

Step 3. Choose between sentences/among phrases in Versions A and B. Justify choices.

\section{Version A}

8. Certain that he has been fired because of his illness, his gayness-or bothHanks decides to go after the firm with a discrimination suit even as his body is starting to give out.
Version B

8. Certain that he has been fired because of his illness, his gayness-or bothHanks decides to go after the firm with a discrimination suit even though his body is starting to give out.
A: So.
B: So. . even though, right? [Negotiation signal]
A: Yeah.

(6) A: Is the result. The next one, even though, even as [Noticing the difference]. Uh, I don't know how to use even as. I seldom use it.

B: Mmm. . . I never. . .

A: Perhaps even as cannot, uhn, connect, uh, sentence... [Awareness of form and function relationship]

B: Yeah, it's also

A: I mean. I don't know. [Negotiation signal]

B: When you think about the context of the first one has what he did, you know, but the second part is, um. . the second part prevent the, the first ... sentence, I mean just the first part, if, if this part is starting to give, uh, he may not, uh, go after the firm, right? [Modified interaction]

A: Yeah.

Attentional processes of recall were also exhibited, almost exclusively during the cloze portion of the tasks. In (7), the pair worked together to remember the item they had chosen earlier (the choosing of the form was documented in [5] and [6]). In (8), the pair compared what was recalled with what was read in the original review passage.

(7) A: As a result... Hanks is summarily dismissed. Certain that he has been fired because of his illness, or his gayness, or both, Hanks decides to go after the firm with a discrimination suit. . even though [Recall of form during completion of cloze]

B: Even though his body is starting to give out.

(8) A: It's difference is even though. This means, mm ... even as means mm ...

B: What is [Negotiation signal]

A: I think this means, um, um, we can with this uh, Hanks decides to do this.

B: Mm-hmm

A: Even as the time... when his body is sta-starting to give out, as in even as, this is, this means even at this time. [Awareness of form and meaning function] 
Beyond these more obvious contributions, the tasks appear to have several unanticipated uses. They can help researchers identify attentional processes directly as they observe and record learners' talk and action. Data from the learners' verbalized decision-making offer an enhancement to retrospective or introspective interviews and protocols that are often used to collect data on the interface of cognition and interaction in L2 learning.

The written cloze component of step 4, in which learners are asked to recall as well as write phrases from the passage sentences that they have compared and chosen, provides a record of their attentional processes. This step documents what the learners recalled if, indeed, they failed to verbalize the phrases that they wrote on the cloze passage or to discuss their decisions and judgments about form, function, and meaning.

Although the tasks and their procedures do not prohibit the kinds of introspective protocol analysis or exit interview appropriate for a monitored, controlled situation, the more relaxed format of texts, tapes, and cloze passages offers a bit of the classroom authenticity needed to sustain teacher and learner participation in long-term studies. Such studies are sorely lacking, but very much needed if the field of SLA is to successfully address questions about the acquisition of forms that defy the learner's mastery in the short term.

Because the tasks are consistent with daily classroom activities and supportive of the subject content curriculum, they bring one additional methodological bonus. They are especially helpful for research on classroom SLA and for research on SLA that requires the long-term, group, or cohort data that classrooms are able to provide. The successful implementation and incorporation of the present tasks in the classrooms for which they were designed is one of the most promising outcomes of our project.

\section{NOTES}

1. Although all six pairs completed all three tasks, a tape recorder malfunctioned during the spot-the-difference task and failed to record one pair's interaction. This accounts for the difference in the amount of data generated for the spot-the-difference task versus the other two tasks.

2. Percentages are rounded to the nearest hundredth.

\section{REFERENCES}

Anger, L., Fuchs, M., Pavlick, C., \& Segal, M. (1988). On your way: Building basic skills in English. London: Longman.

Boyd-Kletzander, R. (2000). Student responsibility in a whole language classroom (Doctoral dissertation, University of Pennsylvania, 2000). Dissertation Abstracts International, 61, 2279.

Brenner, P. (n.d.). [Review of the motion picture Philadelphia]. All movie guide. Retrieved March 16, 2003, from http://www.allmovie.com/cg/avg.dll?p=avg\&sql =1:119903

Brumfit, C. J., \& Johnson, K. (Eds.). (1979). The communicative approach to language teaching. Oxford: Oxford University Press.

Byrnes, H. (2000). Meaning and form in classroom-based SLA research: Reflections from a college foreign language perspective. In J. Lee \& A. Valdman (Eds.), Form and meaning: Multiple perspectives (pp. 125-182). Boston: Heinle \& Heinle. 
Crookes, G., \& Rulon, K. A. (1988). Topic and feedback in native speaker/non-native speaker conversation. TESOL Quarterly, 22, 675-681.

DeKeyser, R. (2003). Implicit and explicit learning. In C. Doughty \& M. H. Long (Eds.), The handbook of second language acquisition (pp. 313-348). Oxford: Blackwell.

Demme, J. (Director). (1993). Philadelphia [Motion picture]. United States: Columbia.

Doughty, C. (2003). Instructed SLA: Conditions, compensation and enhancement. In C. Doughty \& M. H. Long (Eds.), The handbook of second language acquisition (pp. 256-310). Oxford: Blackwell.

Doughty, C., \& Pica, T. (1986). Information gap tasks: Do they facilitate second language acquisition? TESOL Quarterly, 20, 305-325.

Doughty, C., \& Williams, J. (Eds.). (1998). Focus on form in classroom second language acquisition. New York: Cambridge University Press.

Duff, P. (1986). Another look at interlanguage talk: Taking task to task. In R. Day (Ed.), Talking to learn: Conversation in second language acquisition (pp. 147-181). Rowley, MA: Newbury House.

Ebert, R. (1990). Roger Ebert's movie home companion. Kansas City, MO: Andrews and McMeel.

Ellis, J. (n.d.). Philadelphia: An Illusion review by Joan Ellis [Review of the motion picture Philadelphia]. Retrieved March 16, 2003, from http://www.joanellis.com/reviews/PHILADELPHIA.htm

Ellis, R. (2003). Task-based language learning and teaching. Oxford: Oxford University Press.

Fotos, S. (1994). Integrating grammar instruction and communicative language use through grammar consciousness-raising tasks. TESOL Quarterly, 28, 323-351.

Fotos, S., \& Ellis, R. (1991). Communicating about grammar: A task-based approach. TESOL Quarterly, 25, 605-628.

Gass, S. M. (1997). Input, interaction, and the second language learner. Mahwah, NJ: Erlbaum.

Gass, S. M., \& Varonis, E. (1985). Task variation and non-native/non-native negotiation of meaning. In S. M. Gass \& C. Madden (Eds.), Input in second language acquisition (pp. 141-161). Rowley, MA: Newbury House.

Gass, S. M., \& Varonis, E. (1994). Input, interaction, and second language production. Studies in Second Language Acquisition, 16, 283-301.

Harley, B. (1993). Instructional strategies and second language acquisition in early French immersion. Studies in Second Language Acquisition, 15, 245-260.

Harmer, J., \& Surguine, H. (1987). Coast to coast. London: Longman.

Hicks, C. (1994). [Review of the motion picture Philadelphia]. Deseretnews.com. Retrieved March 16, 2003, from http://deseretnews.com/movies/view/1,1257,1425,00.html

Iwashita, N. (2003). Negative feedback and positive evidence in task-based interaction: Differential effects on L2 development. Studies in Second Language Acquisition, 25, 1-36.

Izumi, S. (2002). Output, input enhancement, and the noticing hypothesis: An experimental study on ESL relativization. Studies in Second Language Acquisition, 24, 541-577.

Izumi, S., \& Bigelow, M. (2000). Does output promote noticing and second language acquisition? TESOL Quarterly, 34, 239-278.

Kang, H. (2006). Negative evidence: Its timing, explicitness and linguistic focus as factors in second language acquisition. Doctoral dissertation in preparation, University of Pennsylvania.

Kowal, M., \& Swain, M. (1994). Using collaborative language production tasks to promote students' language awareness. Language Awareness, 3, 73-93.

Krashen, S. (1977). Some issues relating to the Monitor Model. In H. D. Brown, C. Yorio, \& R. Crymes (Eds.), On TESOL '77 (pp. 144-158). Washington, DC: TESOL.

Krashen, S., \& Seliger, H. (1975). The essential characteristics of formal instruction. TESOL Quarterly, 9, 173-183.

Krashen, S., \& Terrell, T. (1983). The natural approach. Oxford: Pergamon.

Leeman, J. (2003). Recasts and second language development: Beyond negative evidence. Studies in Second Language Acquisition, 25, 37-64.

Leow, R. (1997). Attention, awareness and foreign language behavior. Language Learning, 47, 467-505.

Lightbown, P., \& Spada, N. (1999). How languages are learned (Rev. ed.). Oxford: Oxford University Press.

Long, M. H. (1980). Input, interaction, and second language acquisition. (Doctoral dissertation, University of California, Los Angeles, 1980). Dissertation Abstracts International, 41, 5082.

Long, M. H. (1981). Input, interaction, and second language acquisition. In H. Winitz (Ed.), Native language and foreign language acquisition: Annals of the New York Academy of Sciences, 379, $259-278$.

Long, M. H. (1985). Input and second language acquisition theory. In S. M. Gass \& C. Madden (Eds.), Input in second language acquisition (pp. 377-393). Rowley, MA: Newbury House. 
Long, M. H. (1991). Focus on form: A design feature in language teaching methodology. In K. de Bot, R. Ginsberg, \& C. Kramsch (Eds.), Foreign language research in cross cultural perspective (pp. 3952). Amsterdam: Benjamins.

Long, M. H. (1996). The role of the linguistic environment in second language acquisition. In W. C. Ritchie \& T. K. Bhatia (Eds.), Handbook of language acquisition: Vol. 2. Second language acquisition (pp. 413-468). San Diego, CA: Academic Press.

Long, M. H., \& Robinson, P. (1998). Focus on form: Theory, research and practice. In C. Doughty \& J. Williams (Eds.), Focus on form in classroom second language acquisition (pp. 15-63). New York: Cambridge University Press.

Loschky, L., \& Bley-Vroman, R. (1993). Creating structure-based communication tasks for second language development. In G. Crookes \& S. M. Gass (Eds.), Tasks and language learning: Integrating theory and practice (pp. 123-167). Clevedon, UK: Multilingual Matters.

Mackey, A. (1999). Input, interaction, and second language development. Studies in Second Language Acquisition, 21, 557-588.

Mackey, A., \& Gass, S. M. (2005). Second language research: Methodology and design. Mahwah, NJ: Erlbaum.

Mackey, A., Gass, S. M., \& McDonough, K. (2000). How do learners perceive interactional feedback? Studies in Second Language Acquisition, 22, 471-497.

Mackey, A., \& McDonough, K. (2000). Communicative tasks, conversational interaction and linguistic form: An empirical study of Thai. Foreign Language Annals, 33, 82-91.

Mackey, A., Oliver, R., \& Leeman, J. (2003). Interactional input and the incorporation of feedback: An exploration of NS-NNS and NNS-NNS adult and child dyads. Language Learning, 53, 35-66.

McDonough, K. (2005). Identifying the impact of negative feedback and learners' responses on ESL question development. Studies in Second Language Acquisition, 27, 79-103.

Nabei, T., \& Swain, M. (2002). Learner awareness of recasts in classroom interactions: A case study of an adult EFL student's second language learning. Language Awareness, 11, 43-63.

Newton, J., \& Kennedy, G. (1996). Effects of communication tasks on the grammatical relations marked by second language learners. System, 24, 309-322.

Nunan, D. (1989). Designing tasks for the communicative classroom. New York: Cambridge University Press.

Oliver, R. (1995). Negative feedback in child NS/NNS conversation. Studies in Second Language Acquisition, 17, 459-482.

Oliver, R. (2000). Age differences in negotiation and feedback in classroom and pairwork. Language Learning, 50, 119-151.

Philp, J. (2003). Constraints on "noticing the gap": Nonnative speakers' noticing of recasts in NS-NNS interaction. Studies in Second Language Acquisition, 25, 99-126.

Pica, T. (1987). Second language acquisition, social interaction and the classroom. Applied Linguistics, $7,1-25$.

Pica, T. (1991). Classroom interaction, participation, and negotiation: Redefining relationships. System, 19, 437-452.

Pica, T. (1994). Questions from the classroom: Research perspectives. TESOL Quarterly, 28, 49-79.

Pica, T. (2001). The content based curriculum: Does it provide an optimal or optional approach to language learning? In W. Renandya \& N. Sunga (Eds.), Language curriculum and instruction in multicultural societies (pp. 145-174). Singapore: SEAMEO Regional Language Centre.

Pica, T. (2002). Subject matter content: How does it assist the interactional and linguistic needs of classroom language learners? Modern Language Journal, 85, 1-19.

Pica, T., \& Doughty, C. (1985a). Input and interaction in the communicative language classroom: A comparison of teacher-fronted and group activities. In S. M. Gass \& C. Madden (Eds.), Input in second language acquisition (pp. 115-132). Rowley, MA: Newbury House.

Pica, T., \& Doughty, C. (1985b). The role of group work in classroom second language acquisition. Studies in Second Language Acquisition, 7, 233-248.

Pica, T., Holliday, L., Lewis, N., Berducci, D., \& Newman, J. (1991). Language learning through interaction: What role does gender play? Studies in Second Language Acquisition, 13, 343-376.

Pica, T., Holliday, L., Lewis, N., \& Morgenthaler, L. (1989). Comprehensible output as an outcome of linguistic demands on the learner. Studies in Second Language Acquisition, 11, 63-90.

Pica, T., Kanagy, R., \& Falodun, J. (1993). Choosing and using communication tasks for second language instruction. In G. Crookes \& S. M. Gass (Eds.), Tasks and language learning (pp. 9-34). Clevedon, UK: Multilingual Matters. 
Pica, T., Lincoln-Porter, F., Paninos, D., \& Linnell, J. (1996). Language learners' interaction: How does it address the input, output, and feedback needs of L2 learners? TESOL Quarterly, 30, 59-84.

Pica, T., \& Washburn, G. (2003). Negative evidence in language classroom activities: A study of its availability and accessibility to language learners. ITL Journal of Applied Linguistics, 141, 301-344.

Pica, T., Washburn, G., Evans, B., \& Jo, V. (1998, January). Negative feedback in content-based second language classroom interaction: How does it contribute to second language learning? Paper presented at the Annual Pacific Second Language Research Forum, Tokyo, Japan.

Pica, T., Young, R., \& Doughty, C. (1987). The impact of interaction on comprehension. TESOL Quarterly, 21, 737-758.

Pienemann, M. (1981). Psychological constraints on the teachability of languages. Studies in Second Language Acquisition, 6, 186-214.

Plough, I., \& Gass, S. M. (1993). Interlocutor and task familiarity effects on interactional structure. In G. Crookes \& S. M. Gass (Eds.), Tasks and language learning: Integrating theory and practice (pp. 3556). Clevedon, UK: Multilingual Matters.

Renshaw, S. (1994). [Review of the motion picture Philadelphia]. Retrieved January 21, 2005 from http://ofcs.rottentomatoes.com/click/author372/reviews.php?cats $=\& l e t t e r=p \& s o r t b=$ movie\& page $=5 \&$ rid $=768413$

Robinson, P. (1995). Attention, memory, and the noticing hypothesis. Language Learning, 45, 283-331.

Robinson, P. (2003). Attention and memory during SLA. In C. Doughty \& M. H. Long (Eds.), The handbook of second language acquisition (pp. 631-678). Oxford: Blackwell.

Rosa, E., \& O'Neill, M. (1999). Explicitness, intake, and the issue of awareness: Another piece of the puzzle. Studies in Second Language Acquisition, 21, 511-556.

Schmidt, R. (1993). Consciousness, learning and interlanguage pragmatics. In G. Kasper \& S. BlumKulka (Eds.), Interlanguage pragmatics (pp. 21-42). Oxford: Oxford University Press.

Schmidt, R. (2001). Attention. In P. Robinson (Ed.), Cognition and second language instruction (pp. 332). New York: Cambridge University Press.

Schmidt, R., \& Frota, S. (1986). Developing basic conversational ability in a second language: A case study of an adult learner of Portuguese. In R. Day (Ed.), Talking to learn: Conversation in second language acquisition (pp. 237-326). Rowley, MA: Newbury House.

Shah, I. (1999). The sheltered classroom as an environment for second language acquisition (Doctoral dissertation, University of Pennsylvania, 2000). Dissertation Abstracts International, 61, 961.

Swain, M. (1985). Communicative competence: Some roles of comprehensible input and comprehensible output in its development. In S. M. Gass \& C. Madden (Eds.), Input in second language acquisition (pp. 235-253). Rowley, MA: Newbury House.

Swain, M. (1991). French immersion and its offshoots: Getting two for one. In B. Freed (Ed.), Foreign language acquisition and the classroom (pp. 91-103). Lexington, MA: Heath.

Swain, M. (1998). Focus on form through conscious reflection. In C. Doughty \& J. Williams (Eds.), Focus on form in classroom second language acquisition (pp. 64-81). New York: Cambridge University Press.

Swain, M. (2005). The output hypothesis: Theory and research. In E. Hinkel (Ed.), Handbook of research in second language teaching and learning (pp. 471-484). Mahwah, NJ: Erlbaum.

Swain, M., \& Lapkin, S. (2001). Focus on form through collaborative dialogue: Exploring task effects. In M. Bygate, P. Skehan, \& M. Swain (Eds.), Researching pedagogic tasks: Second language learning, teaching and testing (pp. 99-118). London: Longman.

Tomlin, R., \& Villa, V. (1994). Attention in cognitive science and second language acquisition. Studies in Second Language Acquisition, 16, 183-203.

Ur, P. (1981). Discussions that work. New York: Cambridge University Press.

Ur, P. (1988). Grammar practice activities. New York: Cambridge University Press.

Varonis, E., \& Gass, S. M. (1985). Non-native/non-native conversation: A model for negotiation of meaning. Applied Linguistics, 11, 71-90.

VanPatten, B. (1990). Attending to form and content in the input. Studies in Second Language Acquisition, 12, 287-301.

Williams, J., \& Evans, J. (1998). Which kind of focus on which kind of forms? In C. Doughty \& J. Williams (Eds.), Focus on form in classroom second language acquisition (pp. 177-196). New York: Cambridge University Press.

Wong, W. (2001). Modality and attention to meaning and form in the input. Studies in Second Language Acquisition, 23, 345-368. 
Appendix Comparison of Task Directions Across Task Steps

\begin{tabular}{llll}
\hline Steps & \multicolumn{1}{c}{ Spot-the-difference task } & \multicolumn{1}{c}{ Jigsaw task } & Grammar communication task \\
\hline Purpose statement & $\begin{array}{l}\text { The purpose of this activity is to } \\
\text { help you become more accurate and } \\
\text { precise in your speaking and writing, } \\
\text { and to review and edit information } \\
\text { more carefully. }\end{array}$ & $\begin{array}{l}\text { The purpose of this activity is to } \\
\text { help you become more accurate and } \\
\text { precise in your speaking and writing, } \\
\text { and to organize information more } \\
\text { carefully. }\end{array}$ & $\begin{array}{l}\text { The purpose of this activity is to } \\
\text { help you become more accurate and } \\
\text { and to report information accurately. }\end{array}$ \\
& $\begin{array}{l}\text { and } \\
\text { and }\end{array}$
\end{tabular}

Step 1

Materials

Instructions

Step 2

Materials

Instructions

\section{Original passage}

Read the following passage from a review of "name of film." When you are done reading, go to the next page and don't look at the passage again.

\section{Version A or B of original passage}

To do this activity, you have to talk with your partner.

Here is a version of the review passage you just read. The first sentence is the same as it was in the review passage. The other sentences are in a list and in a different order. Some of the other sentences have extra words, different words, or word omissions.

Do not show your version of the review passage to your partner.

Go to the next page and don't turn back. 


\begin{tabular}{lll}
\hline Steps & Spot-the-difference task & Jigsaw task \\
\hline
\end{tabular}

Step 3

Instructions $\quad$ Read your sentence 1 aloud to your partner.

Read your next sentence aloud to your partner.

Listen to your partner's sentence.

Find the differences between these two sentences. Read them aloud to your partner.

Compare your sentence with your partner's.

Choose the sentence that is more accurate and precise.

Give reasons for your choice.

Agree on one choice.

Underline the choice you agreed about.

Repeat steps 2-4 for the remaining sentences
Read your sentence 1 aloud to your partner.

Read the other sentences on your list to yourself.

Find the sentence that goes next.

Read it aloud to your partner.

Listen to your partner's sentence.

Compare your sentence with your partner's.

Choose the sentence that is more accurate and precise.

Give reasons for your choice.

Agree on one choice.

Write the number of the sentence you chose on the line to the left of it. For this sentence, you should write number 2 .

Repeat steps 2-4 for all of the remaining sentences, but write the number 3 , 4 , or 5 on the line to the left of them.
Read your sentence 1 aloud to your partner.

Read your next sentence to yourself. Look at the two items below that sentence. Read them aloud to your partner.

Listen to your partner's two items. There are four items altogether.

Compare your items with your partner's.

Choose the one item out of the four items that makes the sentence more accurate and precise.

Give reasons for your choice.

Agree on one choice out of the four choices.

Underline the one choice you agreed about. Do not write anything on the line in your sentence.

Repeat steps 2-4 for the remaining sentences. 
Reread the passage aloud to each other.

Make sure that you and your partner agree on your choices you numbered.

Make sure that you and your partner have a general understanding of the passage.

You and your partner will be asked to rewrite some of the passage after you go to the next page. Make sure you are ready to do that.

Go to the next page and don't turn back.

\section{Step 4}

Materials

Instructions
Cloze version of original passage, with words and phrases left blank

Either you or your partner have the page with the complete directions. Use that page for now.

Complete the passage in your own words. Try to use the words you and your partner chose, but if you can't remember them, use your own words.

Either you or your partner can be the writer.

Both you and your partner should talk about what you write.

Go to the next page. 
Appendix (Continued)

\begin{tabular}{|c|c|c|}
\hline Steps & Spot-the-difference task & Grammar communication task \\
\hline \multicolumn{3}{|l|}{ Step 5} \\
\hline Materials & Original passage with words and pl & \\
\hline \multirow[t]{5}{*}{ Instructions } & Here is the review passage again. & \\
\hline & The underlined words make the se & and precise. \\
\hline & Compare the passage with the one & ner completed. \\
\hline & $\begin{array}{l}\text { If you and your partner find any diff } \\
\text { other. }\end{array}$ & passage and the passage on page 1 , explain the reasons to each \\
\hline & $\begin{array}{l}\text { Write your reasons next to the num } \\
\text { reasons next to all the numbers. }\end{array}$ & ite as many reasons as you would like. You don't have to write \\
\hline
\end{tabular}

